\title{
o Currículo Mínimo, o ensino de História e o Sistema Estadual de Avaliação no estado do Rio de Janeiro: reflexões sobre os processos de ensino e aprendizagem na escola básica
}

\author{
The Minimum Curriculum, the teaching of History \\ and the State System of Evaluation in the state of Rio de \\ Janeiro: reflections on teaching and learning in basic school
}

Maria Aparecida da Silva Cabral*

\section{Resumo}

Este artigo tem por objetivo analisar o processo de implementação, a partir de 2012, do Currículo Mínimo proposto pela Secretaria de Educação e Cultura, no estado do Rio de Janeiro. Focaliza-se o impacto dessa política educacional no cotidiano escolar, especificamente nas aulas de História do Ensino Fundamental II, com vistas a compreender a maneira como os professores têm organizado a transmissão do conhecimento histórico escolar, bem como seu processo de avaliação nas salas de aula. Tomando como fontes documentais os registros elaborados por licenciandos de História em atividades de Estágio Supervisionado realizadas nas escolas públicas estaduais, bem como os documentos produzidos no âmbito da Seeduc/RJ, constatamos que os professores têm dirigido atenção aos exercícios do Saerjinho e do Saerj durante as aulas de História.

Palavras-chave: ensino de História; currículo; avaliação externa.

\section{Abstract}

This article aims to analyze the implementation process, from 2012, of the Minimum Curriculum proposed by the Department of Education and Culture in the State of Rio de Janeiro. The impact of education policy in the daily school focuses specifically on the lessons of History of Primary Education II, in order to understand the way teachers have organized the transmission of transcripts knowledge as well as its evaluation process in rooms classes. Taking as documentary sources records produced by licensees of History, in supervised training activities in the public schools, and documents produced under the Seeduc/RJ, we found that teachers have directed attention to Saerjinho and Saerj exercises during History lessons.

Keywords: History teaching; curriculum; external evaluation.

\footnotetext{
* Universidade do Estado do Rio de Janeiro (Uerj), Curso de Licenciatura em História e Mestrado Profissional em Ensino de História (PROFHISTÓRIA). Membro do Grupo de Pesquisa Interinstitucional Oficinas de História. Rio de Janeiro, RJ, Brasil. cidacabral123@gmail.com
} 


\section{O PERCURSO DA PESQUISA}

No ano de 2012 a Secretaria de Estado da Educação do Rio de Janeiro (Seeduc) apresentou o documento nomeado 'Currículo Mínimo', que deveria ser utilizado pelos professores em todas as áreas de conhecimento dos ensinos fundamental e médio nas escolas públicas desse Estado. De acordo com os gestores educacionais, àquela ocasião, o propósito de se elaborar um documento dessa natureza seria atender à expectativa da rede relativa à legitimação de uma "base curricular comum" ao ensino desse estado.

Objeto de muitas discussões, polêmicas e até rejeições por parte de uma parcela significativa de professores da rede estadual do Rio de Janeiro, esse documento de referência, desde sua primeira versão realizada em 2011, não deixou de ser pautado nos fóruns sindicais e acadêmicos. Em diferentes contextos os professores da rede pública se posicionaram a respeito da implementação do Currículo Mínimo no âmbito escolar, cuja característica central tem sido a supervisão contínua dos afazeres dos professores (por meio do preenchimento sistemático de planilhas eletrônicas) e a realização de avaliações periódicas produzidas por equipes especializadas, cabendo aos professores das escolas sua aplicação em dias definidos no calendário escolar. ${ }^{1}$

Com a intenção de promover o debate sobre essa política educacional entre os professores, estudantes e pesquisadores do ensino de História, por meio da Associação Nacional de História - Seção Rio de Janeiro (Anpuh-RJ), no seu Encontro Regional em julho de 2012, organizaram uma mesa redonda intitulada Propostas Curriculares de História e Avaliação no Estado do Rio de Janeiro e municípios, coordenada pela Prof ${ }^{a}$ Dra $^{a}$ Helenice Rocha, da Faculdade de Formação de Professores da Uerj, com a participação da Profa Dra Helena Bomeny (subsecretária de Educação do município do Rio de Janeiro), Beatriz Peluso (diretora da articulação curricular da Seeduc), Wesley Karllos Neves Conceição (representante da subsecretaria de gestão da Seeduc) e Cassio Garcez (coordenador de Cultura da Secretaria Municipal de Educação de São Gonçalo), com a finalidade de suscitar questões e reflexões a propósito da política educacional entre os participantes presentes.

As representantes das secretarias fizeram suas explanações acerca das prioridades e desafios postos à educação, no estado do Rio de Janeiro, buscando apresentar ao público quais ações foram valorizadas pelos gestores 
educacionais nos últimos anos; em seguida, os professores e demais participantes fizeram diversas ponderações acerca da proposta do Currículo Mínimo, da Seeduc, bem como da instituição dos cadernos de textos e atividades por área de conhecimento, da Secretaria de Educação do Munícipio do Rio de Janeiro. As perguntas direcionadas às representantes não deixaram de indicar as múltiplas tensões vivenciadas pelos professores no cotidiano escolar durante o processo de ensino e aprendizagem. Mencionaram, nesse sentido, a falta de diálogo com os professores e a desvalorização (por parte das secretarias) da especificidade de cada escola na execução do projeto político pedagógico, apontando para uma faceta da história que as instâncias legais de proposição de currículos insistem em ocultar.

Esse cenário adverso nos motivou a investigar as diversas estratégias adotadas pela Seeduc do Rio de Janeiro para a implantação de sua proposta pedagógica desde 2012, a fim de compreender as maneiras como os professores têm promovido as situações de ensino durante as aulas de História. Interessa-nos saber a forma como os docentes vêm lidando com a proposta pedagógica do Currículo Mínimo.

Para a apresentação dessa discussão utilizamos como fontes primárias os registros sobre o panorama educacional produzidos pelos licenciandos da FFP/ Uerj a partir de sua imersão no ambiente escolar, sob a forma de relatórios de estágios, ${ }^{2}$ perfazendo um total de 28 . Bem como a legislação educacional vigente e a proposta curricular do estado do Rio de Janeiro (Currículo Mínimo). Preliminarmente, o procedimento adotado foi o mapeamento das práticas de ensino e de aprendizagem recorrentemente priorizadas pelos professores durante as aulas de História, registradas pelos licenciandos em suas produções textuais nos anos de 2012 e 2013.

Esse levantamento nos possibilitou a construção de um panorama do que tem sido central em termos de conteúdos de ensino, bem como suas formas de transmissão. Com relação a esse último, a nossa hipótese é de que há uma crescente proposição de atividades a partir do modelo apresentado no Saerjinho (avaliação diagnóstica) e no Saerj, ${ }^{3}$ de modo que as atividades de leitura e produção escrita dos alunos têm sido cada vez mais relegadas a um papel secundário no espaço da sala de aula.

Consideramos que o currículo é um lugar por excelência de disputa social, e por isso mesmo, um objeto privilegiado de análise das políticas educacionais. 
De acordo com Goodson (2008, p.16): “As mudanças na configuração do currículo nos fornecem um valioso teste de tornassol das intenções e propósitos políticos e sociais. Como podemos ver, essas configurações se modificam à medida em que o equilíbrio das forças sociais e o contexto econômico subjacente passam por mudanças cíclicas”.

Diante dessa conjuntura, almejamos analisar as circunstâncias políticas e sociais em que foi proposto o Currículo Mínimo para as escolas estaduais do Rio de Janeiro. Especificamente, o modo como os professores de História têm organizado seus fazeres a partir dessa política educacional. Nesse sentido, uma questão tornou-se norteadora da discussão que nos propomos a fazer: quais os impactos desse modelo de avaliação, instituído para nortear a elaboração das aulas de História?

Nosso objeto de pesquisa foi construído em diálogo com os aportes teórico-metodológicos do campo do currículo e da história das disciplinas escolares, ${ }^{4}$ desdobrando-se para abranger a apresentação da proposição do Currículo Mínimo no estado do Rio de Janeiro e as apropriações das prescrições legais que os professores têm realizado em sala de aula, com vistas a ensinar o conhecimento histórico aos seus alunos. O recorte temporal foi estabelecido em 2012, pois foi nesse momento que a Seeduc finalizou um ciclo de ações, com a publicação dos Currículos Mínimos para todas as áreas do conhecimento.

O contexto das Avaliações Externas no Brasil E SEUS IMPACTOS NOS PROCESSOS DE ENSINO E APRENDIZAGEM NAS ESCOLAS DE EDUCAÇÃO BÁSICA

Os anos de 1990 no Brasil foram marcados pela crescente ofensiva das políticas neoliberais em todos os setores da sociedade. No caso específico da educação, torna-se visível que as políticas educacionais, em suas proposições concretas, têm expressado como e de que modo a lógica do modelo econômico deve se impor aos processos educativos. Nos últimos anos, a participação do Banco Mundial (Bird), da Organização das Nações Unidas para a Educação, a Ciência e a Cultura (Unesco) e do Fundo Monetário Internacional (FMI), por meio de financiamentos sistemáticos e intervenções nos currículos escolares, redefinição de metas e projetos de formação de professores é um sinal do 
quanto essa área se transformou, ao longo da história, em lugar estratégico do capital financeiro internacional. ${ }^{5}$

Vários estudiosos do campo educacional apontam, com suas investigações acerca dessa temática (Tommasi; Warde; Haddad, 1996), que as intervenções das agências internacionais fazem parte de uma ação globalizada, cuja interferência ocorre em áreas divididas por regiões (América Latina e Caribe, Estados árabes, Ásia e Pacífico, Europa e América do Norte) a partir da definição de determinado padrão construído no âmbito da esfera econômica.

No que toca à realidade brasileira, tal fenômeno foi analisado de forma bastante aprofundada por Silva Jr. (2005, p.14), pesquisador que, em sua reflexão a respeito das políticas educacionais nas últimas décadas, desmistifica a ideia de melhoria da qualidade da educação, exaustivamente propagada nos discursos educacionais, associada ao "fortalecimento da cidadania e do aumento das possibilidades de emprego", como resultantes das reformas educativas implementadas pela Lei de Diretrizes e Bases (LDB 9.394/1996), no governo de Fernando Henrique Cardoso. ${ }^{6}$ Para esse autor, tais iniciativas educacionais, em um plano mais amplo, indicam:

a disseminação do novo paradigma de organização das corporações em nível mundial, a desnacionalização da economia brasileira, a desindustrialização, a transformação da estrutura do mercado de trabalho, a terceirização e a precarização do trabalho, a reforma do Estado e a restrição do público conjugada com a ampliação do privado, a flexibilização das relações trabalhistas, o enfraquecimento das instituições políticas de mediação entre a sociedade civil e o Estado (especialmente sindicatos e partidos) para a sociedade do trabalho (sem os direitos sociais conquistados). (Silva Jr., 2005, p.15)

Nesse sentido, constata-se que a educação tem sofrido diretamente os impactos dessa nova reordenação do capital, o que na prática significa uma redefinição dos espaços sociais, que deixam de ser orientados pela lógica pública para serem orientados pela lógica privada. Evidencia-se que desde a promulgação da Lei de Diretrizes e Bases, de 1996 (LDB 9.394/1996), da implantação dos Parâmetros Curriculares Nacionais, de 1998 (PCN), e do Ensino Médio (PCNEM), de 1999, do Fundo Nacional do Desenvolvimento do Ensino Fundamental (Fundef), de 1997, dentre outras medidas jurídico-administrativas, o Estado brasileiro tem instituído uma série de ações que demonstram 
intenção de atender às necessidades do mercado capitalista, com a adoção de avaliações externas, como uma das formas de aferição do que é ensinado nas escolas brasileiras, a construção de políticas meritocráticas para seus profissionais, gerando verdadeiros rankings entre as escolas, além do incentivo à parceria público-privada.

Digno de nota, particularmente, é o enfoque dado aos processos avaliativos e o modo como têm direcionado o trabalho pedagógico das muitas escolas localizadas, por exemplo, nos três grandes estados da região sudeste do país: Minas Gerais, Rio de Janeiro e São Paulo. O sistema de avaliação, como parte integrante de tais reformas nos âmbitos estaduais, visa determinar as prioridades no processo de ensino em termos de conteúdos e valores sociais, tendo assim se constituído como um elemento central das práticas docentes em diversas instituições escolares.

Para Altmann (2001, p.81), os sistemas de avaliação no contexto brasileiro (mas não somente nele) foram implantados, em finais dos anos de 1990, com a finalidade de averiguar metas e padrões de rendimento escolar, assumindo aos poucos centralidade no processo educativo. Assim, de acordo com Altmann (2002, p.83), no que se refere ao Sistema de Avaliação da Educação Básica (Saeb), ele

tem o objetivo de gerar e organizar informações sobre a qualidade de ensino, possibilitando o monitoramento das políticas públicas e a melhoria da qualidade de ensino no país. Ele visa a monitorar a equidade e a eficiência dos sistemas escolares. As provas são realizadas de dois em dois anos com alunos das $4^{\text {as }}$ e $8^{\text {as }}$ séries do ensino fundamental [quintos e oitavos anos] e da $3^{\mathrm{a}}$ série do ensino médio [terceiro ano]. A base desse sistema de avaliação é amostral e também são aplicados questionários contextuais com diretores, professores e alunos. Até 1997, foram realizadas provas de Português, Matemática e Ciências e, em 1999, além dessas, História e Geografia.

Uma leitura mais atenta desses discursos educacionais põe em evidência, contudo, as contradições entre o que as autoridades governamentais propagam como "melhoria da qualidade de ensino" e os processos pelos quais se concretizam tais reformas. É evidente que a tão almejada qualidade somente pode ser viabilizada por meio de investimentos do Estado, pela construção de novos prédios escolares, por incentivos à formação inicial e continuada de 
professores, pela reformulação de currículos etc. Entretanto, observa-se que há prioridade para a legitimação das avaliações externas como instrumentos redirecionadores das práticas docentes - e, portanto, como estratégia de cumprimento do currículo oficial, prática que desconsidera os lugares e as condições em que se realiza o projeto educativo, bem como o papel de seus agentes em sua materialização.

A despeito da institucionalização desse modelo avaliativo nos sistemas de ensino, a pesquisa de Oliveira e Souza (2010, p.817-818), elaborada e aplicada em cinco estados da Federação (Ceará, Bahia, Minas Gerais, Paraná e São Paulo) nos instigou a pensar na pouca eficácia de tal modela, no caso específico do Rio de Janeiro, dado que tal empreendimento se limita a produzir apenas informações, isto é, diagnósticos do que já se sabe acerca da qualidade da educação no país.

\section{A instituição do Currículo Mínimo NO ESTADO DO RIO DE JANEIRO}

Com o argumento de que a rede estadual do Rio de Janeiro deveria ser orientada por um documento que indicasse aos professores "os itens que não podem faltar no processo de ensino e de aprendizagem, em cada disciplina, ano de escolaridade e bimestre" (Seeduc, 2012), a proposta do Currículo Mínimo em sua versão definitiva foi apresentada à comunidade educacional no ano de 2012.

De fato, o Currículo Mínimo é um documento de referência/ou parâmetro para o trabalho do professor, que passou a ser utilizado cotidianamente pela rede estadual de educação desde então. Caracteriza-se por apresentar as competências e as habilidades que devem constar nos planos de cursos e na elaboração das aulas em cada componente curricular. Sua estrutura é composta por três partes articuladas entre si: a apresentação, na qual se narra o processo de elaboração desse documento e sua finalidade atual, a introdução da área específica de conhecimento, e enfim a definição de conteúdos, habilidades e competências, ${ }^{7}$ seguida do tempo previsto que o professor terá para ensinar cada bloco de temas distribuídos por anos de escolaridade.

Certamente, um dos pontos mais polêmicos foi o da participação efetiva do grupo docente no processo de construção desse currículo, principalmente 
porque, desde o período de redemocratização política brasileira nos anos 1980, tornou-se uma "tradição" ${ }^{8}$ no âmbito educativo discutir as reformas educativas com os professores da educação básica. Ao ler esse documento, chama-nos a atenção a ênfase que a Seeduc atribuiu, em vários trechos textuais, à participação de professores especialistas pertencentes à rede estadual na elaboração das versões preliminar e final do Currículo Mínimo. Também convém notar como a coordenação realizada por professores doutores das Universidades do estado do Rio de Janeiro, ${ }^{9}$ como indica o registro abaixo, funciona como forma de legitimação de tal documento entre os docentes da rede estadual fluminense:

A concepção, a redação, revisão e consolidação desse documento foram conduzidas por equipes disciplinares de professores da rede estadual, coordenadas por professores doutores de diversas universidades do Rio de Janeiro, que se reuniram e se esforçaram em torno dessa tarefa, a fim de promover um documento que atendesse às diversas necessidades do ensino na rede. Ao longo do período de consolidação, dezenas de comentários e sugestões foram recebidas e consideradas por essas equipes. Certamente, modificações serão necessárias e pensadas no decorrer do tempo com a aplicação prática desse Currículo Mínimo. (Seeduc, 2012)

A estratégia discursiva utilizada pela Seeduc visa produzir a ideia do consenso na produção do Currículo Mínimo, à medida em que induz o leitor a interpretá-lo como a resposta dos gestores à necessidade da rede estadual de ter um eixo norteador das ações docentes no âmbito da educação pública do estado do Rio de Janeiro. Se com isso pretende criar diversos espaços de diálogos acerca dos temas educacionais, por outro lado, também silencia o dissenso da rede em torno dessa proposta. No texto é frisado, ainda, que as sugestões e comentários foram ponderados pelas equipes gestoras, porém tem-se evidenciado que em nenhum momento foi realizada a devolutiva de tais proposições à rede.

A partir da leitura dos relatórios dos licenciandos em História, temos apurado que muitos professores registraram outra versão para essa história. Quando indagados pelos licenciandos de História a respeito da participação dos docentes na elaboração de sugestões, a maioria deles foi categórica em afirmar que não houve participação qualitativa no processo de consulta pública promovido pela Seeduc. ${ }^{10}$ 
Nascimento (2013, p.10), em um artigo recente sobre a Educação, o Currículo Mínimo e o ensino de História no Rio de Janeiro, adverte sobre a ausência de participação dos docentes no processo de construção desse documento. Sobretudo, para o pouco tempo destinado ao envio de considerações por parte dos professores. Segundo esse autor, em janeiro de 2011 a rede tomou conhecimento por meio do site da Secretaria de que haveria o processo de elaboração do Currículo Mínimo com o envio de sugestões. Todavia, já no mês seguinte (fevereiro) a sua primeira versão foi apresentada à comunidade educativa.

É importante ressaltar que a publicação do Currículo Mínimo no estado do Rio de Janeiro no ano de 2012 visou amarrar uma série de ações que já vinham sendo propostas pela Seeduc ao longo de cinco anos, quando se publicou o ranking das escolas fluminenses. ${ }^{11}$ Nesse sentido, compartilhamos da visão de Barreto (2000, p.2), quando afirma que:

as prescrições governamentais sobre o currículo representam, no entanto, importante acervo de contribuições a ser levado em conta quando se procura entender as tendências que têm predominado no tratamento dos conteúdos veiculados pela escola. De algum modo, essas prescrições procuram responder às demandas feitas à escola por parte da sociedade em face das transformações sociais, culturais e econômicas pelas quais tem passado. Além de veicularem certos valores compartilhados, as orientações curriculares constituem também instrumentos legitimadores de saberes e atitudes, capazes de referendar interesses de grupos e segmentos que disputam a hegemonia na área.

No caso do Rio de Janeiro é perceptível que a divulgação do Currículo Mínimo veio enlaçar uma série de ações que a Seeduc vinha promovendo desde 2008, quando Tereza Porto tornou-se secretária, com a promessa de acabar com o déficit de professores e informatizar as escolas, como forma de melhorar a qualidade da educação pública. Porém, no ano de 2009 a divulgação do Índice de Desenvolvimento da Educação Básica (Ideb), no qual o estado do Rio de Janeiro ficou em penúltimo lugar no ranking nacional, gerou uma crise na educação desse estado, a ponto de essa secretária ter sido substituída pelo economista Wilson Risolia, que está à frente da secretaria desde 2010 até hoje. De acordo com Nascimento (2013, p.6), 
$\mathrm{Na}$ apresentação do novo dirigente da Seeduc/RJ, o governador Sérgio Cabral lançou uma meta ambiciosa: estar entre os 5 melhores estados classificados em 2014. Em janeiro de 2011, o secretário anunciou os pilares da política educacional que seria adotada pelo estado a partir de sua gestão. As manchetes do jornal O Globo apresentavam, sob o título "Choque de Ordem", as metas para os quatro anos seguintes.

Risolia assumiu a Seeduc com a tarefa de promover ações que garantissem a melhoria da educação pública no Rio de Janeiro. Com esse intuito, o secretário vem executando, desde o início a sua gestão, aquilo que compreende como as metas de sua política educacional, ao criar um sistema de bonificação para as escolas, professores e alunos que obtêm os melhores resultados nas avaliações internas e externas (por sinal, bastante questionado pelos professores), ao valorizar a meritocracia entre os profissionais de ensino, ao realocar recursos financeiros, ao promover uma supervisão contínua das ações cotidianas das ações pelas equipes gestoras das Metropolitanas, ao verificar o cumprimento dos conteúdos prescritos no Currículo Mínimo de cada área de conhecimento e determinar que todos os Colégios Estaduais participem nos processos avaliativos, tais como o Sistema Nacional de Avaliação da Educação Básica (Saeb), o Prova Brasil, o Sistema de Avaliação da Educação do Estado do Rio de Janeiro (Saerj) ${ }^{12}$ e Saerjinho, entendidos como necessários.

Em nossa visão, o Currículo Mínimo, uma das vertentes da política educacional que a Seeduc tem elaborado nos últimos oito anos, está em completa sintonia com o contexto que configura o órgão, ao projetar sobre a escola o imperativo de capacidade formativa para o setor produtivo e profissional. Não por acaso o ensino realizado pela escola pública tem sido pautado por muitos setores da sociedade, como o observado em publicações da imprensa de grande circulação. ${ }^{13}$

Em razão disso, o nosso esforço em compreender os processos de materialização dessa política curricular tem nos mobilizado a pensar em alguns aspectos de sua concretude no interior do sistema educativo, perceptíveis nos procedimentos de controle ou imposição de um determinado conteúdo no sistema educativo, a criação de uma estrutura de tomada de decisões que gerencia as ações dos agentes, a distribuição dos materiais, a institucionalização de práticas explicitas de acompanhamento dos fazeres docentes e a avaliação da qualidade do ensino. 
O que os professores ensinam, assim como o tempo destinado para cada bloco de conteúdos, são aspectos do ensino que têm sido supervisionados pela Seeduc sistematicamente, pela atribuição de tarefas ao professor, tais como o preenchimento de campos no endereço eletrônico Conexão Professor ${ }^{14}$. Nessa ferramenta, denominada por Nascimento (2013, p.13) de Cumprimento do Currículo Mínimo, o professor assinala se cumpriu ou não as habilidades/ competências previstas no documento para cada bimestre, salva e as envia ao sistema de gerenciamento das informações da Seeduc. De acordo com os registros de estágio, os dois professores entrevistados pelos licenciados em 2012 foram enfáticos em criticar esse sistema de verificação. O primeiro afirmou que "trata-se de puro controle [por parte da Seeduc], isto é, uma forma de ingerência sobre o trabalho do professor". Por sua vez, o segundo disse que: "não há por parte dos gestores educacionais do Rio de Janeiro uma preocupação efetiva com a qualidade de ensino". ${ }^{15}$

\section{O ENSINO DE HistórIA: TENDÊNCIAS E RECORRÊNCIAS}

Para a disciplina de História em específico, o que predomina no Currículo Mínimo é a perspectiva cronológica de distribuição dos conteúdos/competências/habilidades. Ao longo dos quatro anos finais do ensino fundamental, os marcos temporais instituídos no século XIX funcionam como eixos estruturantes dos acontecimentos humanos, o que convencionalmente na História/ Historiografia denominou-se de modelo quadripartite: Antiguidade, Medieval, Modernidade e Contemporaneidade. Os conteúdos de História da África e China foram agrupados dentro dessas temporalidades.

A Era Vargas, com ênfase no populismo e na ditadura, a Segunda Guerra Mundial (ênfase na bipolarização), a Descolonização da África e os conflitos no Oriente Médio são os conteúdos que devem ser abordados no terceiro bimestre do último ano do ensino fundamental ( $9^{\circ}$ ano), o que implica ensiná-los, de fato, em dois meses de aulas. Para cada um deles estipula-se quais são as habilidades e competências que o professor deve destacar no assunto abordado. Especificamente para esse bloco de conteúdos almeja-se que os alunos aprendam a identificar, compreender, discutir, analisar, questionar, estimular e comparar conteúdos, a partir das situações de ensino e aprendizagem planejadas e promovidas pelos professores durante as aulas de História nas escolas 
de educação básica. Isso é que se pode verificar na reprodução parcial da Tabela 1 que se refere ao segundo tema:

Tabela 1: Conteúdos e Habilidades em História no $9^{\circ}$ ano do Ensino Fundamental

Terceiro Bimestre

\section{Conteúdo A descolonização Afro-asiática e os conflitos do Oriente Médio}

Habilidades/ Questionar as visões preconceituosas sobre a África

Competências e o Oriente Médio

Estimular o respeito à diversidade cultural

Comparar a descolonização africana com a asiática

Tempo para a realização

\section{3 a 6 tempos}

Fonte: Currículo Mínimo, História. Seeduc, 2012.

De acordo com os professores observados pelos estagiários (licenciandos), o item 'Tempo' para o desenvolvimento do conteúdo apresentado tem se configurado um dos fatores de maior dificuldade entre os professores de História. $\mathrm{Na}$ opinião de alguns deles ${ }^{16}$ a rapidez com que se sucedem a explicação de um tema e a elaboração de atividades escritas vem se tornando um elemento de dificuldade na aprendizagem de História. De fato, nas últimas décadas a duração prevista para a disciplina tem sido reduzida nos currículos da educação básica, tendência que não foi acompanhada pela elaboração da matéria dos programas. Ou seja, ao passo que na grade horária das escolas públicas fluminenses o espaço reservado ao ensino de História se reduz, há um aumento significativo da listagem de conteúdos (acontecimentos e conceitos) a serem ensinados. ${ }^{17}$

Apesar de na Introdução do Currículo Mínimo de História ser afirmado textualmente pela equipe gestora da Seeduc que não se trata de ensinar todo o conteúdo listado no documento, mas principalmente apresentar uma seleção de competências e habilidades necessárias à formação crítica do educando, o que se observa é a extensa lista de conteúdos a ser ensinados e avaliados em um tempo exíguo em sala de aula. Exemplos disso podem ser observados nos conteúdos, 
competências e habilidades selecionados para serem ensinados aos alunos do sexto ano do ensino fundamental, tal como os reproduzimos na Tabela 2:

Tabela 2: Conteúdos e Habilidades em História no $6^{\circ}$ ano do Ensino Fundamental

$1^{\circ}$ Bimestre

\begin{tabular}{ll}
\hline Conteúdo & \multicolumn{1}{c}{ Compreensão da História } \\
\hline $\begin{array}{l}\text { Habilidades/ } \\
\text { Competências }\end{array}$ & $\begin{array}{l}\text { Compreender a noção de História } \\
\text { e a naturar o conceito de fonte histórica: suas diferenças } \\
\text { Identificar para cada uma delas }\end{array}$ \\
\hline Conteúdo & $\begin{array}{l}\text { Origem e desenvolvimento do ser humano em } \\
\text { sociedade }\end{array}$ \\
\hline & $\begin{array}{l}\text { Reconhecer o homem como resultado do } \\
\text { desenvolvimento histórico } \\
\text { Comparar as diversas características das primeiras } \\
\text { sociedades coletoras e produtoras } \\
\text { Compreender conceitos e noções de nomadismo, }\end{array}$ \\
Competências & sedentarismo e divisão do trabalho \\
\hline
\end{tabular}

Fonte: Currículo Mínimo, História. Seeduc, 2012.

Esses conteúdos, bem como as habilidades e as competências a eles relacionadas pelo documento, devem ser ensinados às crianças que concluíram o primeiro ciclo de aprendizagem (anos iniciais do ensino fundamental) de fevereiro a março, ou seja, no prazo de um bimestre. Determinação essa que tem representado uma tarefa de enorme complexidade aos professores dos sextos anos. $\mathrm{Na}$ maioria das escolas, os conteúdos nos anos iniciais do ensino fundamental ( $1^{\circ}$ ao $5^{\circ}$ ano) são ensinados por uma única professora que conhece seus alunos pelos nomes e os acompanha diariamente na execução das atividades de leitura e escrita. No caso específico do ensino de História para as crianças prioriza-se a temática da História Local como eixo articulador (Brasil, 2008). Contudo, quando essas mesmas crianças ingressam no segundo segmento/ciclo (do sexto ao 
nono ano), o que se observa é uma apresentação de um conteúdo complexo e às vezes distante das experiências vivenciadas por elas.

$\mathrm{Na}$ concepção da equipe que elaborou a proposta de História do Currículo Mínimo, as aulas dessa disciplina não podem ser associadas ao lugar da memorização, ou seja, "um conjunto de fatos e de datas desconectados da realidade" (Seeduc, 2012, p.4). Porém a indagação que essa situação nos suscita é: como os professores podem promover um ensino problematizador, em que haja construções significativas, com um roteiro imenso a ser seguido e aferido por meio de provas bimestrais construídas por profissionais externos à escola?

Os estudiosos do currículo (Gimeno Sacristán, 2000; Goodson, 1997; 2008), com suas diferentes perspectivas e enfoques metodológicos, têm nos instigado a considerar a educação, bem como seus processos de organização do conhecimento, por meio da relação entre o campo da prescrição, como o lugar das intenções (metas e das finalidades educacionais) e o campo das práticas, como o espaço da materialização. No campo do fazer docente, a forma ou a maneira como os professores do sexto ano lidam com os desafios de se ensinar essa seleção de conteúdos para as crianças mostra uma faceta da complexidade da aprendizagem em História, no contexto da escola pública do Rio de Janeiro.

O uso de linguagens diversificadas - tais como jogos, filmes, desenhos infantis, quadrinhos, clipes musicais - tem sido a estratégia mais valorizada pelos professores que trabalham com essa faixa etária (10 a 12 anos), como destacam os estagiários em seus relatórios. Em um desses registros foi mencionado que a professora fez uso do desenho "Os Croods" como um recurso necessário à compreensão dos significados da sobrevivência dos seres humanos no período da Pré-História. Em seu registro, o licenciando destaca que a professora propunha perguntas aos seus alunos, a partir de algumas questões que avaliava como fundamentais de eles saberem.

Ao ser entrevistada por um licenciando acerca das principais dificuldades apresentadas pelos alunos na aprendizagem em História, uma professora pontuou:

Os alunos têm dificuldade na abstração, imaginação, temporalidade dos processos e eventos. Eles muitas vezes não conseguem se localizar temporalmente, nem 
identificar que aquilo de que está se falando não está solto no tempo e no espaço, que o assunto da aula faz parte de um contexto temporal e espacial. Por exemplo: se pedimos para eles apontarem os continentes afetados pelo Imperialismo, eles [os alunos] não conseguem identificar e acabam apontando países, numa análise de mapa. Outro exemplo: quando se fala de Brasil Império, eles têm dificuldade de imaginar o que seria um Império ou reino e ainda mais que o Brasil foi um. Outra dificuldade é com os séculos: não conseguem associar os séculos aos anos correspondentes. Uma vez um aluno me perguntou se havia séculos maiores que outros, porque ele tinha ouvido que o século XVIII foi maior que os demais. (Entrevista concedida ao licenciando da FFP/Uerj em 2012 e reproduzida em Relatório de Estágio do mesmo ano)

Ensinar os alunos a pensarem historicamente tem sido um dos maiores desafios dos professores dessa disciplina no ensino fundamental, como constatado no fragmento anterior. O que essa professora evidencia em seu depoimento é que os alunos não compreendem a questão temporal, além de não dominarem outros saberes que não necessariamente passam pelo domínio da História, como, por exemplo, a associação de séculos passados aos anos correspondentes. Observa-se, ainda, que a professora confere muita ênfase à dificuldade do aluno na aprendizagem do conhecimento histórico, mas em nenhum momento apresenta uma proposta de ensino que vise superar tal situação.

Verificou-se também que não houve por parte da Seeduc ações de orientação e formação quanto à elaboração de práticas de ensino diferenciadas e/ou formativas quando da publicização do Currículo Mínimo aos professores dessa rede de ensino. Tampouco há indicação nesse documento de como os professores podem organizar a sequência didática ou promover uma situação de aprendizagem. O que se nota é a crítica ao uso exclusivo do livro didático pelo professor de História é veemente por parte da equipe coordenadora de tal instância, como relatado a seguir:

O livro didático continua sendo um dos elementos básicos do cotidiano de professores e alunos. Geralmente, ele está presente em todas as aulas e é partir dele que o professor desenvolve suas atividades. Não é nosso objetivo discutir se os livros são bons ou não. Entendemos que a partir do livro didático, de outros recursos selecionados pelo professor e dos conhecimentos prévios dos alunos e dos professores, é possível construir um plano de curso que alinhe o processo ensino- 
-aprendizagem ao que está proposto nesse documento. Nesse sentido, reforçamos que o livro didático é apenas um dos instrumentos do processo de ensino e de aprendizagem, por condensar muito dos conhecimentos históricos relevantes e acompanhar o aluno em todo o ensino fundamental e médio. (Seeduc, 2012, p.3)

Na cultura docente é perceptível o predomínio do uso dos livros didáticos durante as aulas de História, dado esse que é problematizado em todos os relatórios dos licenciandos. Em parte essa razão pode ser explicada pela política de distribuição gratuita de livros aos alunos, por meio do Plano Nacional do Livro Didático (PNLD), nos últimos anos. Entretanto, seria equivocado avaliar que os professores fazem usos dos livros didáticos sem avaliar se textos, imagens, fontes de informação e atividades presentes em cada capítulo desse material didático são ou não adequados aos seus alunos. Tal assertiva da equipe gestora, em nossa percepção, é muito preocupante, porque produz no leitor certo sentimento de que o professor tem atribuído ao livro didático a tarefa educativa de se decidir o que e como ensinar.

Os licenciandos (estagiários) registraram em seus relatórios que muitos dos professores produzem resumos (estratégias de redução do capítulo do livro), a partir dos textos didáticos e da historiografia, e elaboram com muita frequência atividades escritas com vistas a avaliar se os alunos aprenderam o conteúdo ensinado. Uma prática predominante observada pelos licenciandos, e constante em suas produções, é a elaboração de exercícios sob os moldes dos parâmetros do Saerjinho, que ocorrem nos três primeiros bimestres de cada ano letivo e do Saerj ${ }^{18}$ e são aplicados em dezembro como fechamento do ciclo de avaliações.

\section{Algumas CONSIDERAÇÕES}

Visamos com este texto apresentar os resultados parciais obtidos com a análise de relatórios produzidos por licenciandos em História, no âmbito da Universidade do Estado do Rio de Janeiro, Faculdade de Formação de Professores da (Uerj-FF), que realizaram seus estágios supervisionados em escolas públicas pertencentes à rede estadual de educação, em escolas localizadas em São Gonçalo (região metropolitana do Rio de Janeiro). 
Como a finalidade do Estágio Supervisionado em História é proporcionar que seus licenciandos, a partir da vivência no cotidiano escolar, compreendam os processos de ensino e de aprendizagem no âmbito da sala de aula, bem como as apropriações do currículo instituído pela Secretaria de Educação por professores, observamos que um ponto recorrente nos registros deles é o fato de a proposta do Currículo Mínimo nesse estado ter instituído um ritmo de ensino e processos de verificação da aprendizagem.

Priorizamos a problematização da materialização da proposta pedagógica da Seeduc do Rio de Janeiro para o ensino de História no ambiente escolar apresentando as recorrências de certas práticas de ensino no processo de didatização (concepção, planejamento, transmissão e avaliação) do conhecimento histórico escolar a partir da institucionalização do Currículo Mínimo para a área de História no ano de 2012.

Para finalizar, estamos certos de que os professores são centrais na viabilização de uma dada política curricular, ainda que as secretarias de educação no contexto atual tenham ignorado solenemente esse princípio na elaboração de seus currículos. A retórica adotada pelo governo, nesses últimos anos, de que as reformas educacionais foram/são necessárias para que se atinja a meta da melhoria da educação pública, não tem conseguido convencer os docentes da rede estadual. Além disso, o fato de convidar alguns professores como representantes da voz docente, desconsiderando os locais onde as escolas estão inseridas e seus agentes, sem dúvida não foi a melhor tática para persuadir o corpo docente quanto à qualidade da proposta da Seeduc nos dois últimos anos.

\section{REFERÊNCIAS}

ALTMANN, Helena. Influências do Banco Mundial no projeto educacional brasileiro. Educação e Pesquisa, São Paulo, v.28, n.1, p.77-89, jan./jun. 2002.

BARRETTO, Elba Siqueira de Sá (Org.) Os currículos do ensino fundamental para as escolas brasileiras. Campinas, SP: Autores Associados; São Paulo: Fundação Carlos Chagas, 2000. (coleção Formação de Professores).

BRASIL. Secretaria de Educação Fundamental. Parâmetros Curriculares Nacionais: História. Brasília: MEC/SEF, 1998.

CHERVEL, André. História das disciplinas escolares: reflexões sobre um campo de pesquisa. Teoria \& Educação, n.2, p.177-229, 1990. 
GIMENO SACRISTÁN, José. O Currículo: uma reflexão sobre a prática. Trad. Ernani F. da F. Rosa. Porto Alegre: ArtMed, 2000.

GOODSON, Ivor F. A construção social do currículo. Lisboa: Educa, 1997. . As políticas de currículo e de escolarização: abordagens históricas. Trad. Vera Joscelyne. Petrópolis, RJ: Vozes, 2008.

HOBSBAWM, Eric; RANGER, Terence (Org.) A invenção das tradições. Rio de Janeiro, Paz e terra. 1984.

NASCIMENTO, Thiago R. A educação, o ensino de história e o currículo mínimo do estado do Rio de Janeiro: currículo escrito, em ação e formação de professores. História \& Ensino, Londrina, v.19, n.2, p.87-114, jul./dez. 2013.

OLIVEIRA, Romualdo Portela de; SOUSA, Sandra Zákia. Sistemas estaduais de avaliação: uso dos resultados, implicações e tendências. Cadernos de Pesquisa, São Paulo, v.40, n.141, p.793-822, set./dez. 2010.

RIO DE JANEIRO (Estado). Secretaria de Estado de Educação. Currículo Mínimo História. Rio de Janeiro, 2012.

SILVA JR., João dos Reis. Pragmatismo e populismo na educação superior: nos governos FHC e Lula. São Paulo: Xamã, 2005.

TOMMASI, Lívia de; WARDE, Miriam Jorge; HADDAD, Sérgio (Org.) O Banco Mundial e as políticas educacionais. São Paulo: Cortez; PUC-SP/Ação Educativa, 1996.

\section{NOTAS}

${ }^{1}$ Cada escola no início do período letivo aprova em sua reunião de planejamento as atividades que serão desenvolvidas durante o ano, encaminhando-as à Metropolitana para a análise da equipe pedagógica e consecutivamente a homologação. Os dias das avaliações (Saerj), as reuniões de pais, as reuniões de conselho de classe, o período de recuperação são algumas das deliberações que constam em tal calendário.

${ }^{2}$ Cabe esclarecer que tais documentos foram produzidos pelos licenciandos em História, que realizaram seus estágios supervisionados nas escolas de ensino fundamental e médio, a partir do sexto período (ou semestre), de 2012 a 2013, sob a supervisão de um professor da Universidade. Ao elaborarem os relatórios de estágio, os licenciandos visam apresentar informações acerca do cotidiano da sala de aula, especificamente a didática do professor regente, a interação com a turma, os materiais de ensino privilegiados na proposição de atividades e os processos avaliativos utilizados durante as aulas de História.

${ }^{3} \mathrm{O}$ Saerjinho foi o nome designado pela equipe gestora para a aplicação de exames bimestrais em cada disciplina durante o ano letivo. Para a Seeduc, o Saerjinho tem por finalidade preparar o aluno para a realização do exame anual (Saerj). 
${ }^{4}$ Utilizamos as contribuições de Goodson (1997; 2008), acerca do entendimento do currículo como uma série de negociações e tensões sociais, e de Chervel (1990), sobre as finalidades das disciplinas educativas no âmbito escolar.

${ }^{5}$ A predominância de agências internacionais como a Unesco, o Bird e o FMI no delineamento das políticas educacionais brasileiras para a educação básica foi problematizada por diversos autores nos últimos anos. Para aprofundar esse assunto, ver os trabalhos de: Altmann, 2002.

${ }^{6}$ Fernando Henrique Cardoso esteve à frente da Presidência do Brasil de 1994-2002, sendo o responsável pelo encaminhamento de uma série de medidas vistas como neoliberais no campo da educação.

${ }^{7}$ Nessa proposta, as competências e as habilidades são valorizadas e devem ser priorizadas no ensino de determinados conteúdos, de modo que ao professor cabe a organização de situações de ensino e aprendizagem no espaço escolar que propiciem aos alunos vivências significativas.

${ }^{8}$ Fazemos uso do termo tradição, à luz da perspectiva de Hobsbawm e Ranger (1984), para explicitar que no cenário educacional brasileiro a discussão e apresentação das propostas curriculares aos professores tornaram-se uma prática institucionalizada incorporada ao longo dos últimos anos aos procedimentos dos gestores educacionais.

${ }^{9}$ A primeira versão de História foi divulgada em 2011 aos professores da rede, contando com a seguinte equipe de elaboração: coordenação da Profa ${ }^{2} r^{a}$ Gracilda Alves (UFRJ) e Prof $^{a}$ Dr $^{a}$ Denise da Silva Menezes do Nascimento (UFJF) e professores colaboradores dos Colégios Estaduais do Rio de Janeiro: Fabrício Lobato Alexandrino (Baltazar Bernadino), Ingrid Ribeiro Couto (Liceu Nilo Peçanha), Maria Cristina Fonseca Ribeiro Vidal (Pandiá Calógeras), Shirley da Silva Bastos (Antônio Gonçalves), Wesley Karllos Neves Conceição (Bernardo Sayão) e Mariana Ferreira Melo (André Maurois). No ano de 2012 houve uma pequena reestruturação na equipe de elaboração, com a criação da figura do articulador. A Prof $^{a} \operatorname{Dr}^{a}$ Gracilda Alves continuou na coordenação da equipe e a Prof ${ }^{a} \operatorname{Dr}^{a}$ Denise da Silva Menezes do Nascimento passou a fazer parte da instância de articulação. No que toca aos colaboradores da rede estadual, somente Wesley Karllos Neves Conceição permaneceu no grupo, que passou a ser composto também pelos professores Daniel Wanderson Ferreira (Monteiro Carvalho), Paulo Mauricio Pimenta Pereira Leite (Julia Kubtschek), Priscilla Leal Mello (Aureliano Leal), Sabrina Machado Campos (Manuel de Abreu) e Talita Nunes Silva (Duque Costa).

${ }^{10}$ Essa afirmação é feita com base na análise de 28 relatórios de estágio elaborados pelos licenciandos, a partir de um roteiro prévio apresentado pela professora de Estágio Supervisionado durante as aulas no espaço da Universidade. Esse documento é constituído pelos seguintes itens: visões dos professores de História acerca da proposta do Currículo Mínimo (ênfase na relação entre currículo prescrito e executado), processo de ensino e aprendizagem, uso de materiais didáticos, condições estruturais das escolas e principais dificuldades enfrentadas pelos professores no exercício do magistério. 
${ }^{11}$ Para aprofundar esse assunto ver Nascimento, 2013.

${ }^{12}$ A título de esclarecimento, cabe mencionar que o SAERJ é realizado no estado do Rio de Janeiro desde 2008 e a proposta do Currículo Mínimo foi apresentada em sua versão final somente em 2012. Para mais informações consultar: http://www.rj.gov.br/web/seeduc/ exibeconteudo? article-id=843535; Acesso em: 1 nov. 2014.

${ }^{13}$ Nossa afirmação se ancora na percepção e em leituras das seções destinadas à Educação em jornais impressos de grande circulação na atualidade, como O Estado de S. Paulo, Folha de S. Paulo e O Globo.

${ }^{14}$ Os Currículos Mínimos de todas as áreas de conhecimento podem ser acessados no site http://www.conexaoprofessor.rj.gov.br/curriculo_identificacao.asp; Acesso em: 3 nov. 2014.

${ }^{15}$ Para ilustrar essa análise, recortamos parte das entrevistas concedidas aos licenciandos que foram citadas em seus relatórios de estágio, com as devidas autorizações dos professores.

${ }^{16}$ Em dez relatórios há referência aos posicionamentos dos professores quanto ao fator tempo como um elemento que dificulta a abordagem qualitativa de um determinado assunto nas aulas de História.

${ }^{17}$ É evidente que há um número reduzido de aulas para essa disciplina, se realizada uma comparação quantitativa com as disciplinas Matemática e Língua Portuguesa; ambas possuem cinco tempos semanais de aula, ao passo que História dispõe apenas de três.

${ }^{18}$ Esse é o resultado que a Seeduc tem utilizado para o Iderj.

Artigo recebido em 28 de agosto de 2015. Aprovado em 29 de dezembro de 2015. 